\title{
Effects of climatic factors on the sedimentation trends of Tarbela Reservoir, Pakistan
}

\author{
Nausheen Mazhar ${ }^{1,2}$ (D) Ali lqtadar Mirza ${ }^{2} \cdot$ Sohail Abbas ${ }^{3} \cdot$ Muhammad Ameer Nawaz Akram $^{4} \cdot$ Muhammad Ali $^{5}$. \\ Kanwal Javid ${ }^{2}$
}

Received: 2 November 2020 / Accepted: 30 December 2020 / Published online: 12 January 2021

(C) The Author(s) 2021 OPEN

\begin{abstract}
The study explores the factors affecting the sedimentation trends in the surrounding catchment area of the Tarbela Dam for the period 1980-2017, specifically rain and temperature. Furthermore, this study also investigates the seasonal effects of sediment loads coming into the reservoir from 2007 to 2012. The statistical techniques were applied for the estimation of the effects of climate (rainfall and temperature) on the sedimentation and the inflow of Tarbela Dam and its surrounding catchment area. The results revealed that sediment deposition pattern points toward the greater bed elevation at 7-12 range lines that lie near the Main Embankment Dam, also that Barandu River carried more bulk of inflow to the Indus, as compared to Siran River and thus contributed a greater amount of sediments to the reservoir. Summer monsoon season also contributed to the greatest bulk of sediments to the Tarbela Dam and its surrounding catchment area. The regression confirmed that for one degree increase in temperature there will be a 7 Million Acre Feet (MAF) increase; for a $1 \mathrm{~mm}(\mathrm{~mm})$ increase in rainfall there will be a 1 MAF decrease and for a 1 Cusec increase in the inflow coming into the reservoir, there be a $4 \mathrm{MAF}$ increase in sedimentation of the reservoir. Thus, the contribution of the temperature in sediment generation is found to be greater than rainfall. The study recommended that for the proper functioning of Tarbela Dam, the shift in the climate of the Upper Indus Basin (UIB) might be regularly monitored as rising temperatures in UIB would result in greater glacial melt and hence greater sediments to settle down into the reservoirs downstream.
\end{abstract}

Keywords Tarbela Dam · Main embankment dam · Monsoon season · Rangelines

\section{Introduction}

Reservoirs around the world are facing the challenges of sedimentation. For the year 1986, it was estimated that there is an economic loss of US\$ 6 billion each year due to the loss of $1 \%$ of the world's gross reservoir storage [1]. The process of sedimentation begins right from the movement of runoff, either generated from rainfall, wind or snowmelt. The reservoirs serve as an efficient sediment trap because the velocity of water is very low here. Sediment inflow has a strong impact on the reservoir's storage capacity. Most reservoirs across the globe suffer from the menace of sedimentation because an increase in the flow depth and consequently a decrease in the flow velocity cause a reduction in the capacity of the reservoir's sediment transport, which in turn leads to settling of the bulk of incoming sediments. Bed elevation of reservoir rises, and aggravation is caused as the sediments get deposited across the entire reservoir. These sediments are deposited in a deltaic formation, with coarser sediments in the headwater area of the reservoir,

$\triangle$ Nausheen Mazhar, nausheen.mazhar@lcwu.edu.pk|'Department of Geography, Lahore College for Women University, Lahore, Pakistan. ${ }^{2}$ Department of Geography, Government College University, Lahore, Pakistan. ${ }^{3}$ Department of Geography, Climate Research Institute (CRI), Konkuk University, Seoul, Republic of Korea. ${ }^{4}$ State Key Laboratory of Information Engineering in Surveying, Mapping and Remote Sensing (LIESMARS), Wuhan University, Wuhan, China. ${ }^{5}$ National Centre of Excellence in Geology, University of Peshawar, Peshawar, Pakistan. 
while the finer sediments can get transported to the dam by the density currents [2].

Seasonal variations in the catchment area have great impacts on the amounts of sediment generation. [3] mention that seasonal shifts in rainfall patterns cause changes in the physical, biological and chemical characteristics of the hydrologic systems. Similarly, the gradual rising temperatures and prolonged summers in the catchment area can lead to increased glacial melting that in turn lead to greater sediment generation. According to [4], sedimentation is a parameter to define the capacity of the reservoirs, and sedimentation yield controls the amount of sedimentation reaching a reservoir. [5] indicates the sediment yield as "the sediment discharge through a river outlet per unit catchment area per unit time." Sediment yield in turn is dependent upon the rate of soil erosion in the catchment area.

The sediment load increase can cause a reduction in the water quality of a river as it carries pollutants, leads to reduction in light penetration, a reduction in the river depth and in extreme cases clogging of the gills of the fish $[6,7]$. [7] states that the quality of the surface water deteriorates due to increase in sediment loads that the rivers carry, and thus, it is essential to control the rate of soil erosion by understanding the processes involved in the transportation of suspended sediments.

The amount of sediment generation is also dependent upon factors such as land use practices, removal of vegetal cover, which causes a reduction in infiltration and leads to increased runoff [8 and 9], whereas the uncertain pattern of sedimentation of reservoirs is attributed to both inflow, sediment flux, particle size, geometry and structure of reservoir and their operational rules [10, 31]. The varying loads of sediments are dependent on the boundary condition.

The river Indus carries huge loads of sediments and has one of the highest rates of sediment transport reported in the literature [11]. This is because it passes through Himalayas and Karakoram, both geomorphically extremely active regions [12]. These are young fold mountains that are subject to rapid degradation. These are prone to tectonic instability, have high relief and receive most of the runoff from the glaciers [13]. According to [14], the average annual inflow to Tarbela is 81,000 million cubic meter $\left(\mathrm{Mm}^{3)}\right.$, while the annual sediment inflows vary between 100 and 300 metric tons (MT) for 1967-1996. [15] are of the view that the sediments from the catchment area reach Tarbela reservoir where due to insufficient velocity favorable conditions for particle settling are generated, due to which reservoir's important storage capacity is lost. Eighty percentage of the total sediment load gets deposited in the Tarbela reservoir during July-August [15]. [16] states that $97 \%$ of the sediments are carried during the large flows in summer season between May and September, and a peak is witnessed because of the snowmelt in July and August.

[17] state that snowmelt with $35-44 \%$ inflow input, contributes more inflow to the Indus River than glacial melt, with a percentage of $25-36 \%$. The authors further affirm that just upstream Tarbela Reservoir, Indus River carries annual flow, which is $70 \%$ composed of melt waters. Among this $70 \%, 44 \%$ is obtained through snowmelt, while $26 \%$ through glacial melt. The contribution to river discharge through glacial melt is decreasing rapidly due to loss of glacial masses at higher elevations. These losses can be attributed to changes in mean annual temperature of UIB.

Snow and glacial melt contribute $90 \%$ of the inflow coming into the Tarbela reservoir. These glaciers crush the rocks and provide the bulk of the sediments that get settled in the reservoir [18]. [19] enlist the factors that have an impact on the trap efficiency: fall velocity of various sediment particles, flow rate of these sediments and their velocity through the reservoir. [20] explain that UIB has three regions based on runoff sources, Region 1 is temperature controlled and consists of glacierized sub basins, Region 3 gets its runoff from monsoon and western disturbances while the Region 2 is a combination of the above two sources of runoff. Based on the difference in sources of runoff, sediment generation rate and time also differ. Sediment yield also increases with the increase in the drainage area, for, e.g., "from $355 \mathrm{t} \mathrm{km}^{-2} \mathrm{yr}^{-1}$ at Kharmong to $1197 \mathrm{t} \mathrm{km}^{-2} \mathrm{yr}^{-1}$ at Besham Qila": ( $p 382$ ), and the main reason is the contribution of runoff by many small and steep catchments.

Tarbela's trap efficiency is very high because its shape leads to the deposition of almost entire incoming sediment. According to estimates, since 1974 there has been a 30\% decrease in the live storage of the reservoir till 2009. This drastic decrease in live storage means a decrease in the supply of irrigation water and less production of hydroelectricity [16]. The trapping efficiency of Tarbela is among the highest in the world's reservoirs. Thus, it is necessary to monitor the factors that affect sedimentation. [20] identify that between Besham Qilla and Tarbela the three most important tributaries that bring the bulk of sediments into the dam are Gorband, Barandu and Siran. Their research provides the specific sediment yield of these rivers at different gauging stations, which is very helpful for detailed analysis.

Tarbela has been filled to its maximum elevation, i.e., $472 \mathrm{~m}$ in almost all years. Usually, the reservoir reaches its maximum level by August 20 and remains full till midSeptember. During this period, the reservoir is well above the delta and a deposit of new sediments is formed on top of the existing delta surface. Sedimentation is a cyclic 
process. The reservoir starts providing water for irrigation after September, and the reservoir reaches its minimum level in April or early May, and it is in late May or early June when the snowmelt starts, and high flows start again [18].

Since its impoundment in 1974, the reservoir has lost $20 \%$ of its gross capacity and nearly $40 \%$ of the original dead storage. The live storage is being lost and sediments threaten to block the intake tunnels dealing with irrigation and power generation [12]. Although many studies have been conducted on sedimentation trends of Tarbela reservoir, however, the relationship between the key variables affecting sedimentation and the study of sediment load input season-wise have been a neglected area in the literature. The objective of this study is to explore the effects of rainfall and temperature on the sedimentation and the inflow of Tarbela Dam and its surrounding catchment area for the period of 1980-2017. Furthermore, this study also investigates the seasonal effects of sediment loads coming into the reservoir from 2007-2012.

\section{Materials and methods}

\subsection{Characteristics of Tarbela Dam, Pakistan}

The Tarbela Dam is basically named after the town of Tarbela which is located in Haripur and Swabi district. Its coordinates are $34^{\circ} 05^{\prime} 23^{\prime \prime} \mathrm{N}-72^{\circ} 41^{\prime} 55^{\prime \prime} \mathrm{E}$ (Fig. 1). It is the largest natural dam in the world which was constructed over Indus River and completed in 1976. It is used to produce hydroelectric power, for irrigation purposes and to flood control. The average daily temperature varies from summer to winter. In the summer, it goes up to $40{ }^{\circ} \mathrm{C}$ in June and lowest in winter at $3{ }^{\circ} \mathrm{C}$. In monsoon season, relative humidity also plays its role and exceeds up to $50 \%$.

\subsection{Data analysis}

Secondary data of the variables of bed elevation, inflow of sediments, main reservoir sedimentation, daily inflow of water in the reservoir and deposition/erosion at longitudinal profile points were collected from the office of the Tarbela Dam Project, Haripur, for a period of thirty years, i.e., 1980-2010. In order to have an estimate of the amount of sediments being contributed by the two tributaries of Indus, Siran and Barandu rivers that lie just north of Tarbela reservoir, the annual discharge datasets were obtained for the years 1980-2010, for the Daggar and Phulra gauging stations from WAPDA regional office. Statistical analysis, including comparative line and bar graphs, multiple linear regression, ANOVA and correlation analysis between sedimentation and inflow variables were performed in SPSS 16.0.
The rate of sedimentation in Tarbela reservoir is dependent upon inflow coming into the reservoir, temperature and rainfall in the catchment area north of Tarbela. The relationship between dependent variable sedimentation with the independent variables of inflow, rainfall and temperature was explored through multiple linear regression model in SPSS. Multiple linear regression (MLR) has also been used in various other international studies focused on sedimentation and bed load analysis. [21 and 32] applied MLR to prove linear relationship between variables, in this case river discharge and suspended sediment load of River Rio Chama, USA. [22] used MLR in their study for bed load analysis of Malaysian rivers.

\section{Results and discussion}

\subsection{Deposition/erosion range line-wise}

The analysis of the bed elevation data concludes that the bed elevation had drastically increased since Tarbela's inception along all the range lines (Fig. 2). The location of the range lines of the Tarbela Dam reservoir is shown in Fig. 3.

During the period of 2011-2012, the elevation of underwater delta was found to be maximum between range lines 7 to 12 , as has been shown in Fig. 4, meaning that deposition was more near the (Main Embankment dam) MED. As we move away from MED the deposition decreases and even reaches a point of erosion between rangeline $131 / 4-13 \frac{3 / 4}{4}, 17$ and 21-27.

\subsection{Factors affecting the sedimentation at Tarbela Reservoir}

Scarce vegetation along with the steepness of the valley walls contributes to the higher sediment generation rate in the catchment. The bulk of inflow determined the amount of sediments that will be carried with it. The amount of inflow coming into the reservoir is highly dependent on the seasonal shift. Sedimentation is greatly influenced by factors like slope, amount of inflow, season, geology of the catchment area, etc. However, in the current study only the impact of tributaries, temperature and rainfall in the catchment area, i.e., Upper Indus Basin (UIB), the seasonal bulk of sediments and inflow coming into the reservoir has been analyzed. 


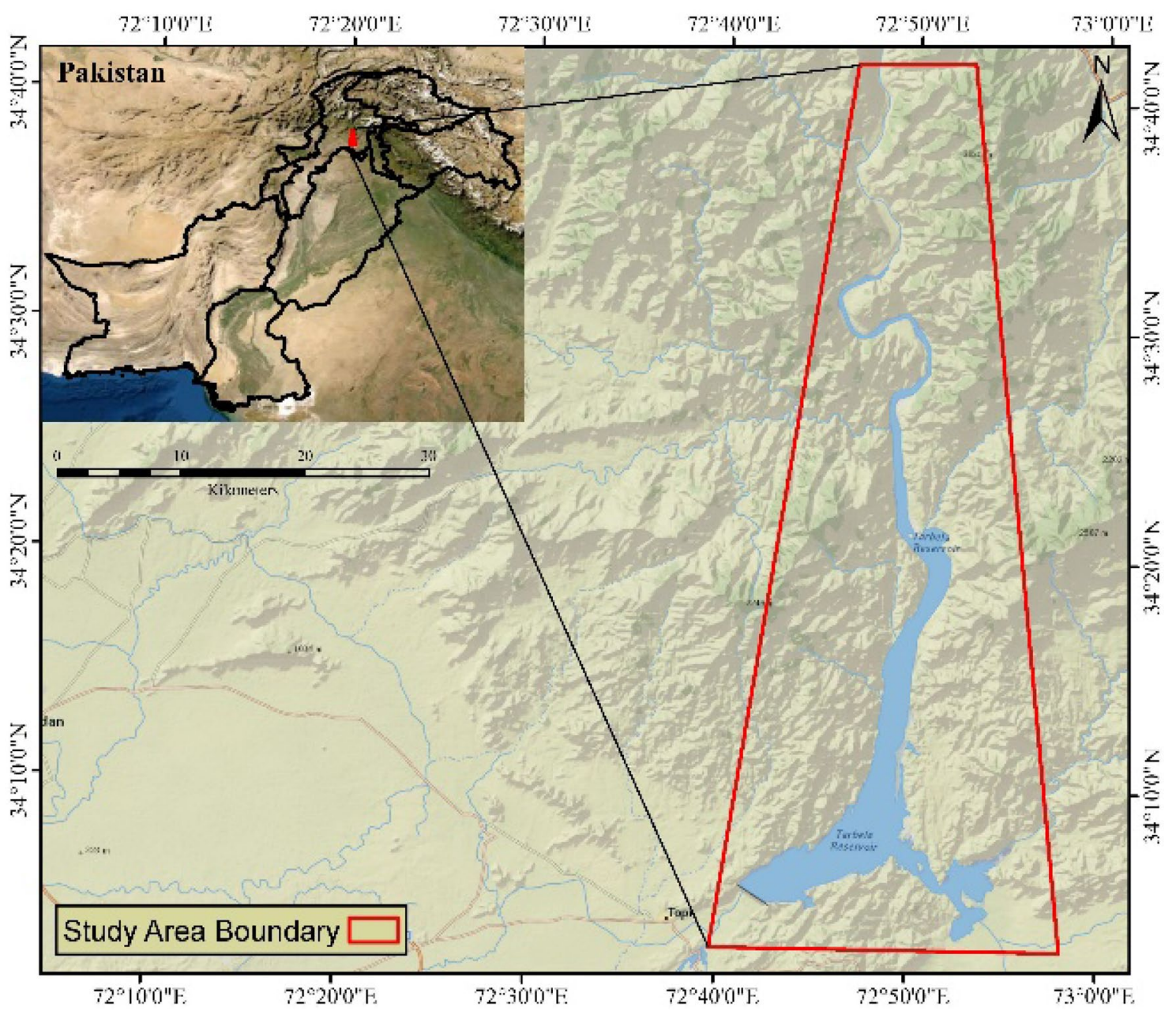

Fig. 1 Study area map

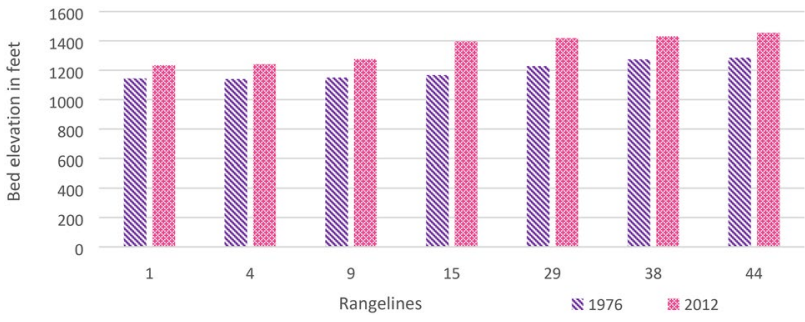

Fig. 2 Tarbela reservoir bed elevation along range lines for the period of 1976 and 2012

\subsection{River Siran and Barandu}

River Siran and Barandu, gauged at Daggar and Phulra gauging stations (Fig. 5), just south of Besham Qilla gauging station, are the tributaries of Indus north of Tarbela reservoir. Thus, they also contribute to the addition of the sediment load of Tarbela reservoir. Among the two tributaries, (Fig. 6) the annual average discharge of river Barandu is higher than river Siran.

Figure 6 depicts the great fluctuations in the discharge of river Barandu, which is an important tributary of Indus in terms of sediment contribution, since it lies near Tarbela reservoir.

The annual average discharge at Phulra was highest in 2010, when Pakistan experienced its worst flood, and lowest in the year 2001, the year in which Pakistan was facing drought conditions. On the other hand, Siran River contributes less water and sediments to the Indus and the graph presents little fluctuations in the discharge of Siran during 1993-2012.

\subsection{Season-wise comparison of sediment inflow, outflow and trapped sediments}

Figure 7 presents the sediment inflow, in the reservoir for three main seasons, i.e., winter, summer and monsoon, from 2007-2012. The seasonal analysis of sediment 


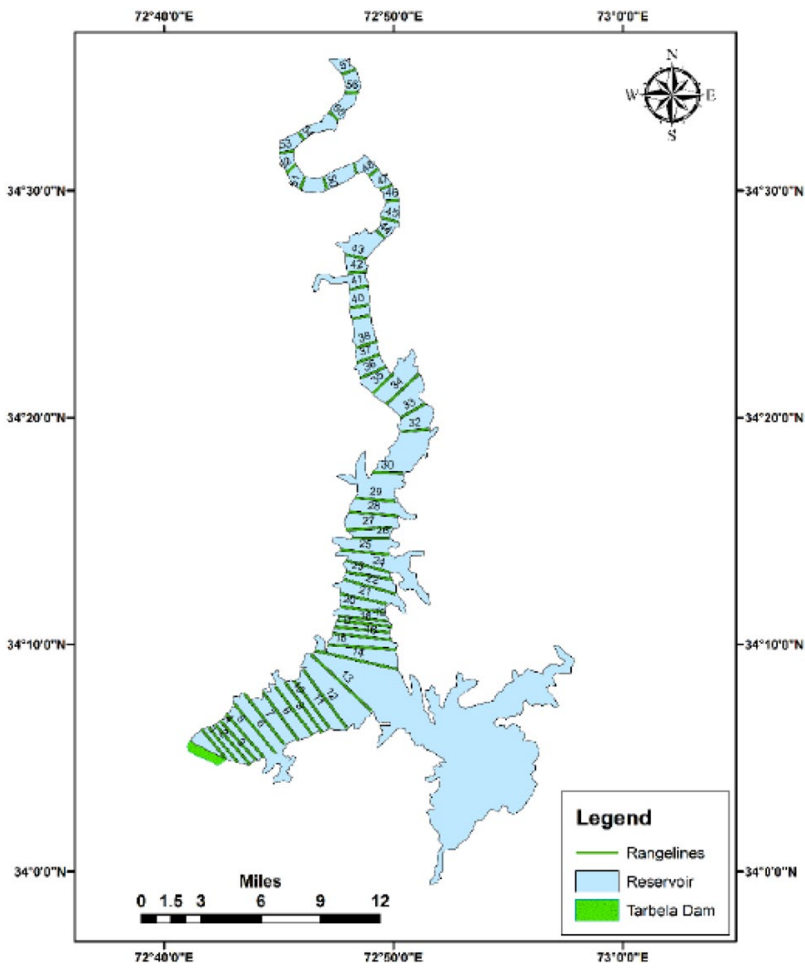

Fig. 3 Location of range lines of Tarbela Reservoir

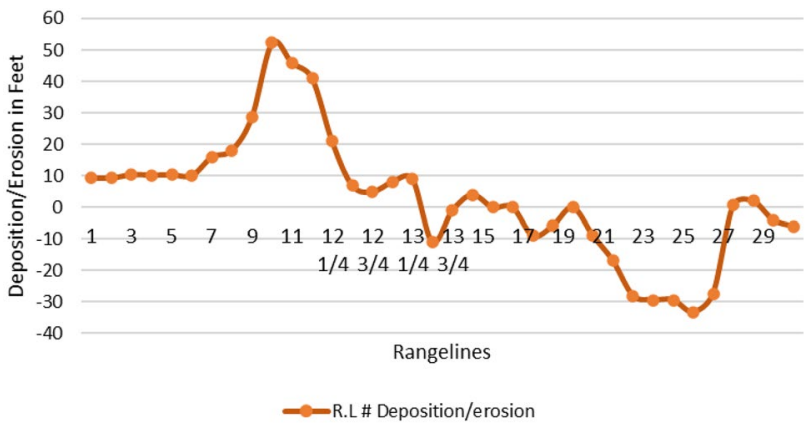

Fig. 4 Deposition/erosion at longitudinal profile points from range line 1-30 for the year 2011-2012

inflow in the years under study proves maximum input of sediments in the monsoon season. 2010 the worst flood year for Pakistan contributes 1401.619 acre feet of sediments to the reservoir in the monsoon season, while in the same year only 1.77 acre feet of sediments and 99.332 acre feet of sediments got settled in the reservoir during winter and summer season, respectively. [3] also concluded similar findings of higher suspended loads of sediments in Chalok River of Malaysia, during the wet periods.

[23] supports the fact that the three months of JulySep are most influential in deciding the amount of sedimentation that will get trapped in the reservoir each year, by mentioning that $80 \%$ of the sediment of Tarbela gets trapped in the reservoir during these three months.

[16] is also of the view that $97 \%$ sediments are carried during heavy flows witnessed between May and September, while another peak is witnessed due to snowmelt in July and August. In the current study, Nov to Feb are classified as winter season, March till June is classified as summer and July-Oct as the summer monsoon season.

\subsection{Relationship between sedimentation and inflow in Tarbela}

Figure 8 presents the scatter plot showing the variation of sedimentation with the inflow. The correlation is significant at 0.01 level, with a Pearson correlation value of 603 , proving a strong correlation between sedimentation and inflow coming into the Tarbela reservoir.

Figure 9 indicates the strong positive correlation between the two variables. As the inflow in the dam increases, so does the amount of incoming sediments. This relation is especially evident in the years 1984, 1990, 1994, 1996, 1999, 2006, 2010, 2014 and 2016 (Fig. 10).

The MLR model was applied after all the five assumptions of the model were met. Next the overall significance of the model was tested through ANOVA. The $p$ value was $<0.001$ proving that the model is significant.

The adjusted $\mathrm{R}$ square value in the model summary is: 0.439 . Almost $43 \%$ of variability in sedimentation is accounted by the temperature and rainfall in the upper Indus basin and the amount of inflow coming into the Tarbela reservoir. Based on the $\beta$ coefficients (one goes with each predictor), (based on the model summary) the equation for the regression line is presented in Eq. 1.

$\begin{aligned} y= & -0.146+0.007 \text { (temprarure) } \\ & -0.001 \text { (rainfall) }+0.004 \text { (inflow) }\end{aligned}$

Independent variable coefficient is statistically nonsignificant except for inflow as model predicts that: For every $1^{\circ}$ increase in temperature causes 0.007 MAF increase in sedimentation. Similarly, with every $1 \mathrm{~mm}$ increase in rainfall, there will be a decrease in sedimentation of 0.001 MAF. However, inflow increase of 1 Cusec coming into the reservoir causes $0.004 \mathrm{MAF}$ increase in sedimentation. The significance values in the coefficient table also proves inflow as a variable to have higher significant $p$ value of 0.000 . Thus, the regression model which was applied using sedimentation as dependent variable, and temperature, rainfall and inflow as independent variables, presents meaningful relationships between the dependent variable with the independent variables. It can be concluded that among the three independent variables, inflow is the one 


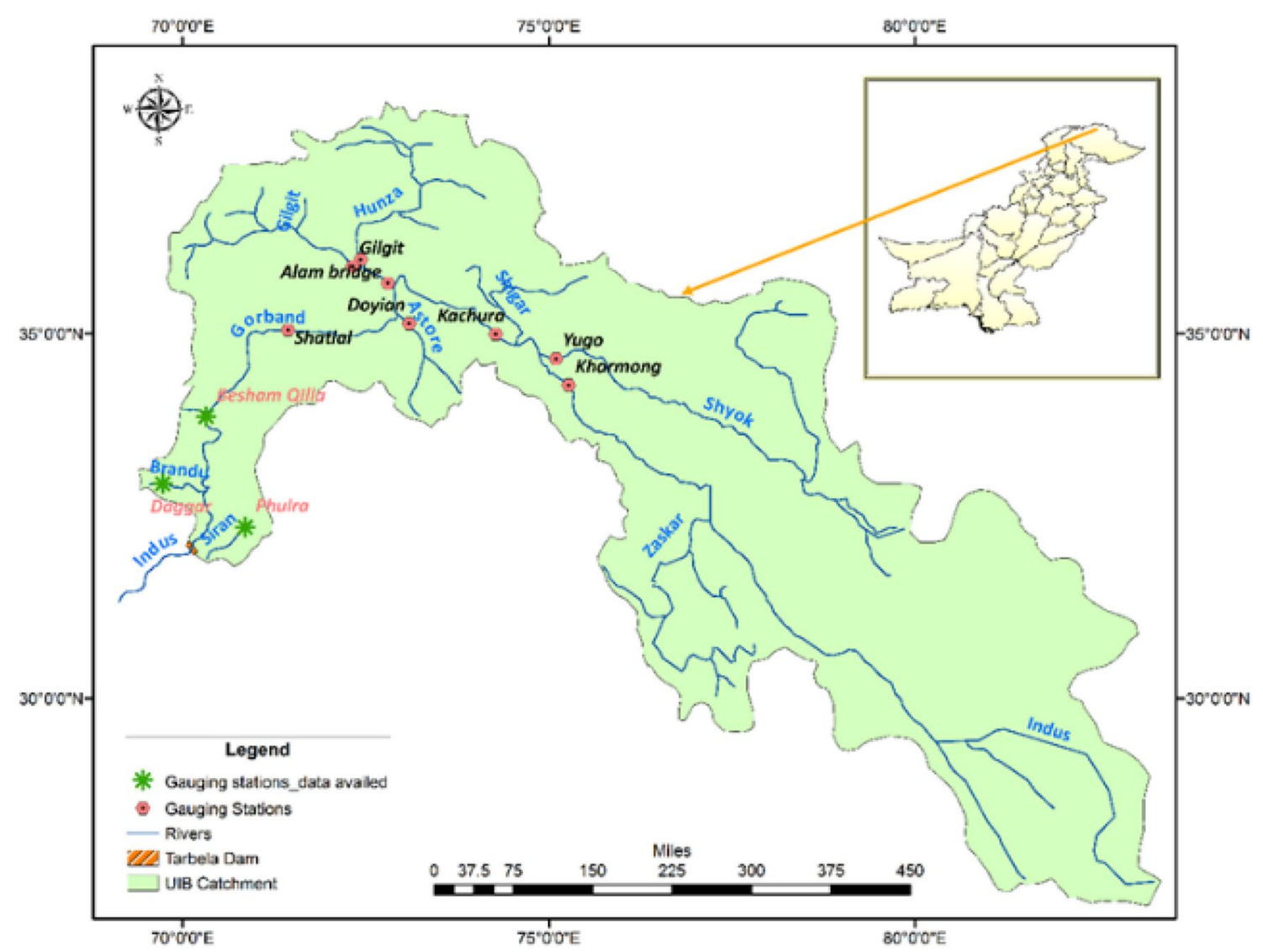

Fig. 5 Upper Indus Basin: location of gauging stations

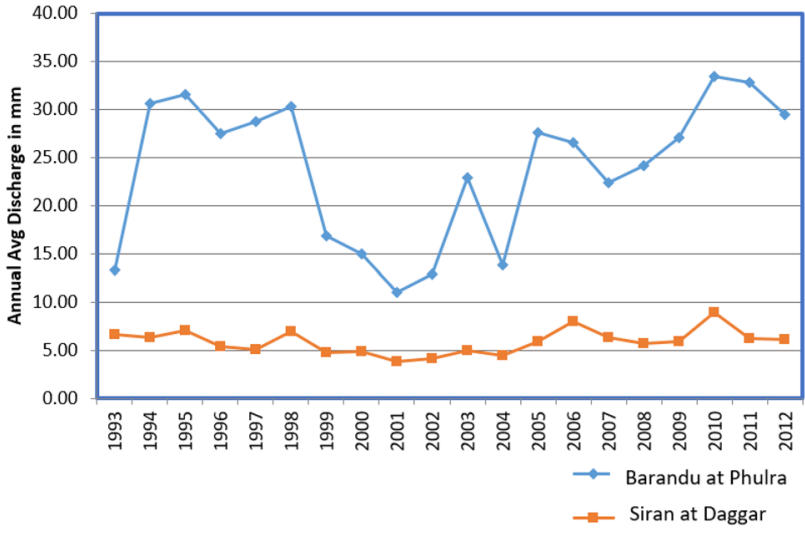

Fig. 6 Annual average discharge at the Daggar (Siran) and Phulra (Barandu) for the period of 1993-2012

with the strongest positive relation with sedimentation, with the highest significance.

Thus, we can say that while monitoring sedimentation trends of Tarbela reservoir, a seasonal link with bulk of sediment, i.e., maximum sediments get settled in the reservoir during monsoon season, was identified. The second

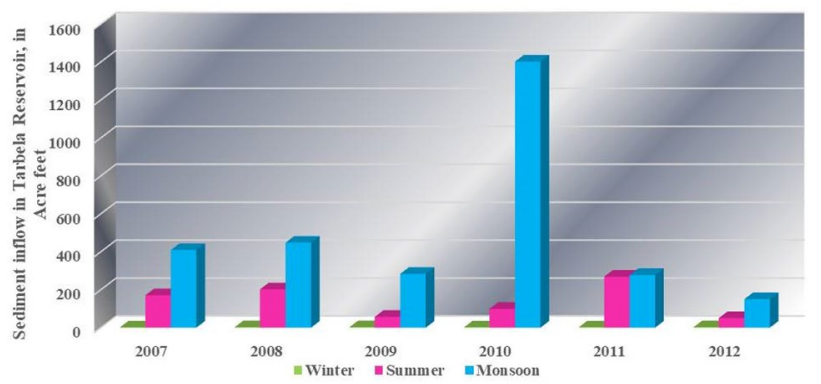

Fig. 7 Season-wise sediment inflow in the Tarbela reservoir

finding explores a strong correlation between inflow and sedimentation. Therefore, in the monsoon season when the flow is maximum due to rains and snowmelt, the incoming sediment rate is also high. The third finding was that among the three independent variables of inflow, temperature and rain affecting the dependent variable of sedimentation, 1 Cusec rise in inflow results in a $0.004 \mathrm{MAF}$ increase in sedimentation with a high significant $p$ value of 0.000 , while $1^{\circ}$ rise in temperature will lead to $0.007 \mathrm{MAF}$ increase in sedimentation but with lesser significance of 


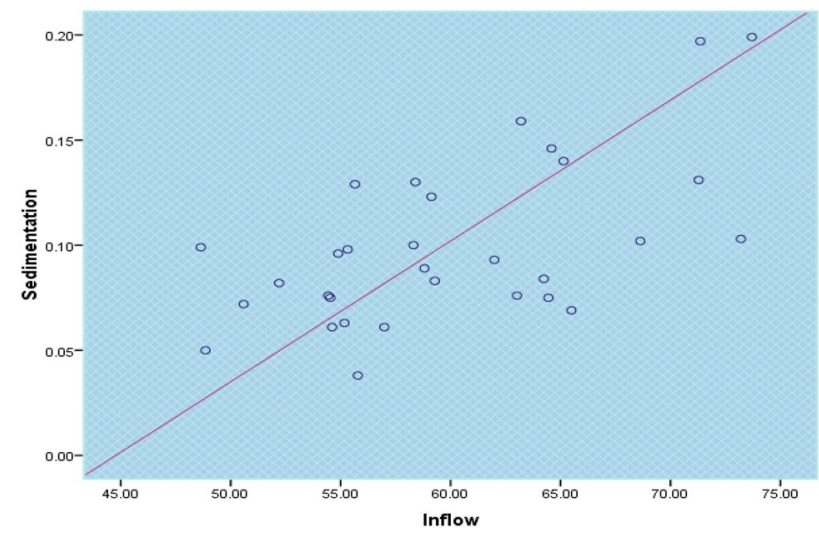

Fig. 8 Scatter plot show relation between sedimentation and inflow coming into Tarbela reservoir

0.409 . However, $1 \mathrm{~mm}$ increase in rainfall there will be a $0.001 \mathrm{MAF}$ decrease in sedimentation with a significance of 0.043 .

The sedimentation rate of Tarbela reservoir was proved to be dependent on seasons with maximum being recorded in the monsoon. A very strong positive correlation of sediment with inflow was proved with the help of Pearson correlation with a $p$ value $<0.001$. [24] also concluded in his study that summer monsoon is the season when runoff in Indus is at its peak. The reason of course is the high snowmelt runoff accompanied by monsoon rains; this situation leads to peak floods. Thus, if the runoff in Indus will be maximized in the summer monsoon, so would be the inflow and sediments coming in Tarbela reservoir, as proven in this study. It can be suggested that monsoon season sediment generation needs to be monitored on regular basis and yearly monsoon sediment generation trends must be established for efficient management of sedimentation in this reservoir.

The annual average sediments deposited in the reservoir for the period of 1980-2012 was 0.100 MAF. The MLR model proved that among the three independent variables of temperature, rainfall and inflow, inflow as a variable had the strongest impact on the sedimentation of Tarbela reservoir, so much so that 1 Cusec rise in inflow coming into the reservoir can cause $0.004 \mathrm{MAF}$ increase in sedimentation. Rainfall, as a variable, has negative impact on sedimentation as River Indus is more dependent on snow and glacial melt for its runoff, than on rains. Therefore, future studies are recommended to be focused on the glacial retreat in the UIB region and proposed models to forecast resultant sediment generation rate.

\section{Conclusion and recommendations}

In the current study, the statistical techniques were applied for the estimation of the effects of climate (rainfall and temperature) on the sedimentation and the inflow of Tarbela Dam and its surrounding catchment area for the period of 1980-2017. The results revealed that summer monsoon season contributed to the greatest bulk of the sediments to Tarbela for the

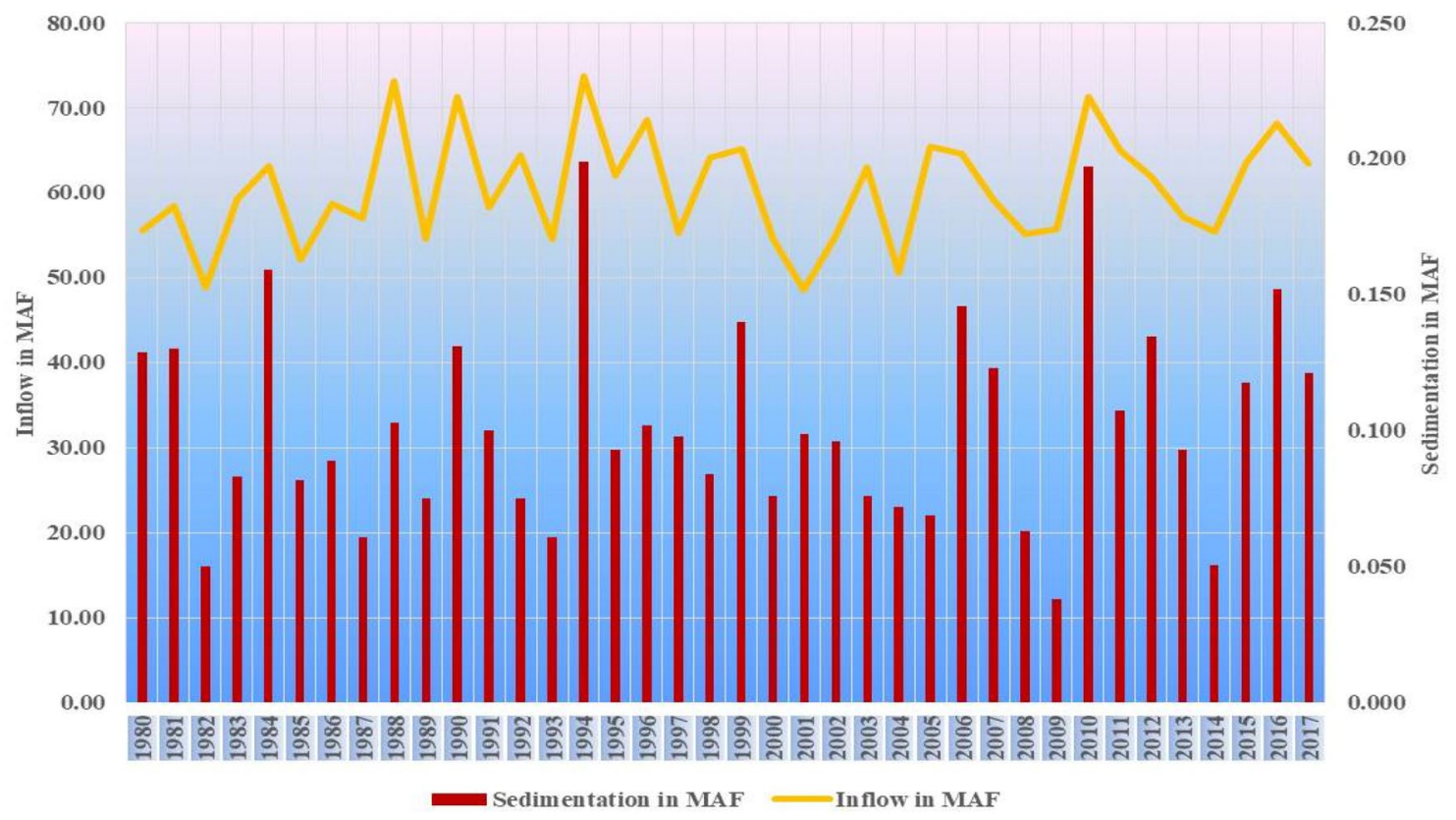

Fig. 9 Relationship between sedimentation and inflow in Tarbela Reservoir during period of 1980-2017 


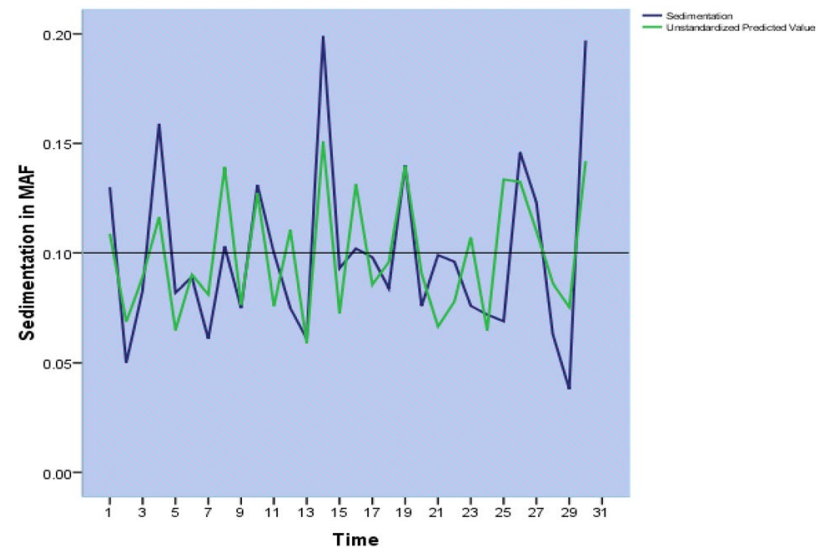

Fig. 10 Trend line showing current and predicted sedimentation rate

years 2007-2012. During the summer monsoon season of 2010, 1401.619 acre feet of sediments were found to be deposited in the reservoir. [15] mentioned a similar inflowing sediment bulk for Tarbela reservoir, where $80 \%$ of its sediment load were received during July and August. [3] also reported similar increased sediment inflow for Chalok River, Malaysia, during the wet season. This study has examined the relationship between sedimentation of Tarbela reservoir with rainfall, temperature and inflow, for the period of 1980-2017 and MLR proved inflow in the reservoir as a variable, have most a strong relationship with sediment generation. The increase of sedimentation due to increase of 1 Cusec rise in mean annual inflow coming into the reservoir, boost toward the harmful results, since the flow of the Indus and its tributaries is high in summer monsoon, thus the sediment load gets transported downstream and most of it ends up settling in Tarbela reservoir due to its high trap efficiency. Resultantly, the loss of the operational capacity of the dam has an installed capacity of $3478 \mathrm{MW}$ and has the potential to be enhanced to $6300 \mathrm{MW}$ in near future [25].

In order to keep the Tarbela Dam functioning for a long time, it is recommended that measures must be taken to monitor the changing climatic trends that are leading to fluctuations in temperature and precipitation means of UIB, which would result in changes of runoff, magnitude and the amount of sediment generation. It is recommended that sediment budget of UIB may be formulated by focusing on the relation between the source region and the delivery process. For future studies in the region, it is recommended that gauging network may be made extensive and more reliable. Proper watershed management of Indus is recommended as inflow of sediments in a reservoir might be controlled to great extent by carefully planned watershed management.
Acknowledgement This paper has been presented at the15th All Pakistan Geographical Conference, held at Karachi, Pakistan, 21-23 April 2018. The authors are grateful to Mr. Ghulam Ali Varaich, Senior Officer Electronics, Tarbela Reservoir, for assistance extended during field survey.

\section{Compliance with ethical standards}

Conflict of interest The authors declare that they have no conflict of interest.

Open Access This article is licensed under a Creative Commons Attribution 4.0 International License, which permits use, sharing, adaptation, distribution and reproduction in any medium or format, as long as you give appropriate credit to the original author(s) and the source, provide a link to the Creative Commons licence, and indicate if changes were made. The images or other third party material in this article are included in the article's Creative Commons licence, unless indicated otherwise in a credit line to the material. If material is not included in the article's Creative Commons licence and your intended use is not permitted by statutory regulation or exceeds the permitted use, you will need to obtain permission directly from the copyright holder. To view a copy of this licence, visit http://creativecommons .org/licenses/by/4.0/.

\section{References}

1. Mahmood K (1987) Reservoir sedimentation: impact, extent, and mitigation. Technical paper (No. PB-88-113964/XAB; WORLDBANK-TP-71). International Bank for Reconstruction and Development, Washington, DC

2. Hosseinjanzadeh $\mathrm{H}$, Hosseini K, Kaveh K, Mousavi SF (2015) New proposed method for prediction of reservoir sedimentation distribution. Int J Sediment Res 30(3):235-240

3. Shamsuddin AS, Zaharin AA, Razman SF, Ghazali FM (2014) Seasonal variations and yearly trend evaluations of sedimentation loads: a case study at Chalok River, Terengganu. Malaysia Env Asia 7(1):45-56

4. Dutta $S$ (2016) Soil erosion, sediment yield and sedimentation of reservoir: a review. Model Earth Sy and Env 2(3):123

5. ASCE (1982) Task Committee. Relationships between morphology of small streams and sediment yields. J. Hydr. Div, 1328-1365

6. Park JH, Inam E, Abdullah MH, Agustiyani D, Duan L, Hoang TT, Sao V, Wirojanagud W (2011) Implications of rainfall variability for seasonality and climate-induced risks concerning surface water quality in East Asia. J Hydrol 400(3-4):323-332

7. Nu-Fang F, Zhi-Hua S, Lu L, Cheng, (2011) Rainfall, runoff, and suspended sediment delivery relationships in a small agricultural watershed of the three Gorges area. China Geomorphol 135(1-2):158-166

8. Chen X, Bao S, Li H, Cai X, Guo P, Wu Z, Zhao H (2007) LUCC impact on sediment loads in subtropical rainy areas. Photogramm Eng Rem S 73(3):319-327

9. Beuselinck L, Govers G, Hairsine PB, Sander GC, Breynaert M (2002) The influence of rainfall on sediment transport by overland flow over areas of net deposition. J Hydrol 257:145-163

10. Hassan M, Shamim MA, Sikandar A, Mehmood I, Ahmed I, Ashiq SZ, Khitab A (2015) Development of sediment load estimation models by using artificial neural networkig techniques. Environ Monit Assess 187:1-13 
11. Meybeck M (1976) Total mineral dissolved transport by world major rivers/transport en sels dissous des plus grands fleuves mondiaux. Hydrol Sci J 21(2):265-284

12. Tate EL, Farquharson FA (2000) Simulating reservoir management under the threat of sedimentation: the case of Tarbela dam on the river Indus. Water Resour Manag 14(3):191-208

13. Collins DN, Hasnain SI (1995) Runoff and sediment transport from glacierized basins at the Himalayan scale. IAHS Publications-Series of Proceedings and Reports-Intern Assoc Hydrological Sciences, 226: 17-26

14. TAMS (1998) Tarbela Dam Sediment Management Study: Main Report by TAMS Consultants in association with HR Wallingford, March

15. Ahmed KB, Sanchez M (2011) A study of the factors and processes involved in the sedimentation of Tarbela reservoir. Pakistan Environ Earth Sci 62(5):927-933

16. Roca M (2012) Tarbela Dam in Pakistan, Case Study of Reservoir Sedimentation. In Proceedings of the International Conference on Fluvial Hydraulics-River Flow 201. San Jose, Costa Rica

17. Mukhopadhyay B, Khan A (2015) A reevaluation of the snowmelt and glacial melt in river flows within Upper Indus Basin and its significance in a changing climate. J Hydrol 527:1 19-132

18. Haq IU, Abbas ST (2006) Sedimentation of Tarbela and Mangla Reservoirs. In: Proceedings of the 70th Annual Session of the Pakistan Engineering Congress, vol 2, no 4

19. Strand RI, Pemberton EL (1982) Reservoir Sedimentation. Technical Guideline for Bureau of Reclamation (USA)
20. Ali KF, De Boer DH (2007) Spatial patterns and variation of suspended sediment yield in the upper Indus River basin, northern Pakistan. J Hydrol 334(3-4):368-387

21. Ghorbani MA, Hosseini SH, Fazelifard MH, Abbasi H (2013) Sediment load estimation by MLR, ANN, NF and sediment rating curve (SRC) in Rio Chama river. J Civil Eng Urban 3(4):136-141

22. Sinnakaudan SK, Ghani AA, Ahmad MS, Zakaria NA (2006) Multiple linear regression model for total bed material load prediction. J Hydraul Eng 132(5):521-528

23. Sanchez M, Khawaja A (2008) Sedimentation Processes, River Morphology and Reservoir Modelling. In Xèmes Journées nationales Génie Côtier-Génie Civil

24. Dahri ZH, Ahmad B, Leach JH, Ahmad S (2011) Satellite-based snowcover distribution and associated snowmelt runoff modeling in Swat River Basin of Pakistan. Proc Pak Acad Sci 48:19-32

25. Nawaz M, Zulfiqar F, Bilal M, Khan AZ (2016) Improving Efficiency and Reliability of Protection System of Tarbela Power Station. In MATEC Web of Conferences, EDP Sciences 54

Publisher's Note Springer Nature remains neutral with regard to jurisdictional claims in published maps and institutional affiliations. 